NASA Technical Memorandum 103269

\title{
Preliminary Results from the Advanced Photovoltaic Experiment Flight Test
}

David J. Brinker and Russell E. Hart, Jr.

Lewis Research Center

Cleveland, Ohio

and

John R. Hickey

The Eppley Laboratory, Inc.

Newport, Rhode Island

Prepared for the

21st Photovoltaic Specialists Conference

sponsored by the Institute of Electrical and Electronics Engineers

Kissimmee, Florida, May 21-25, 1990

\section{N/Sh}


PRELIMINARY RESULTS FROM THE ADVANCED PHOTOVOLTAIC EXPERIMENT FLIGHT TEST

David J. Brinker and Russe11 E. Hart, Jr. NASA Lewis Research Center

Cleveland, Ohio 44135

John R. Hickey

The Eppley Laboratory, Inc.

Newport, Rhode Island 02840

\begin{abstract}
The Advanced Photovoltaic Experiment is a space flight test designed to provide reference cell standards for photovoltaic measurements as well as to investigate the solar spectrum and the effect of the space environment on solar cells. After a flight of 69 months in low earth orbit as part of the Long Duration Exposure Facility set of experiments, it was retrieved in January, 1990. The electronic data acquisition system functioned as designed, measuring and recording cell performance data over the first 358 days of flight; limited by battery lifetime. Significant physical changes are also readily apparent, including erosion of front surface paint, micrometeoroid and debris cratering and contamination.
\end{abstract}

\title{
INTRODUCTION
}

The Advanced Photovoltaic Experiment (APEX) is a space flight test designed to provide reference cell standards for photovoltaic measurements as well as investigate the solar spectrum and the effect of long term exposure of solar cells to the space environment. APEX was launched into low earth orbit as part of the Long Duration Exposure Facility (LDEF) set of experiments on April 6 of 1984 with a designed on-orbit lifetime of one year. Delays in retrieval due to changes in Space Shuttle manifest priorities and the Challenger accident greatly extended the flight time, with retrieval occurring on January 12 of this year. This unplanned sixfold increase in flight time has resulted in the inability to meet some of the original mission objectives, but will yield extremely valuable and rare data concerning the survivability of solar cells in low earth orbit.

In this paper we present the preliminary results from the Advanced Photovoltaic Experiment. The original objectives of the experiment, the design and fabrication of APEX and the solar cell complement will be discussed in detail. The results of the preliminary analysis of the flight data and the physical changes apparent will be included. The paper will close with the plan for future study. 


\section{BACKGROUND}

The Long Duration Exposure Facility was designed to provide economical access to low earth orbit for experiments which did not require telemetry or large amounts of electrical power. The LDEF Project, conceived and subsequently executed by the NASA Langley Research Center, was approved in 1974 to utilize the two-way transportation capability of the Space Shuttle. An announcement of opportunity was made by Langley in 1976 and a project plan for a photovoltaic experiment was written by the Lewis Research Center. The principal investigators at Lewis initially responsible for APEX were Henry W. Brandhorst, Jr. and Americo F. Forestieri. R. E. Hart became principal investigator during the middle stages of the experiment fabrication and remained so until early 1989.

A contract was awarded to The Eppley Laboratory, Inc. of Newport, Rhode Island in September, 1977 for definition and fabrication of the Advanced Photovoltaic Experiment. The original launch date for LDEF was in 1980. However, delays in Shuttle development delayed the actual deployment by the Challenger (the STS-41C mission) to April 7, 1984.

The Long Duration Exposure Facility is a thirty foot long, fourteen foot diameter, twelve-sided structure. Experimental trays, 34 inches wide by 50 inches long, were bolted onto the 12 sides, with 34 inch square trays attached to both ends. The satellite was placed into a circular orbit of 256 nautical miles altitude with an inclination of $28.5^{\circ}$. The satellite was gravity-gradient-stabilized with one end of the cylinder always facing the Earth and one of the twelve sides, designated Row 9, alway perpendicular to and facing the direction of orbital motion. It was this row, the leading edge, which saw the full effect of the ram, including atomic oxygen flux and micrometeoroid and debris. APEX, designated experiment S0014, occupied position E9, the second experimental tray from the space end on the leading edge. In Figure 1 LDEF can be seen in orbit, moments after deployment from the shuttle. APEX is visible as a black tray on the same row as the two trunnions with skid plates for fastening LDEF to the Shuttle payload bay.

The retrieval of LDEF was planned for February of 1985. However, changes in payload manifest priorities delayed retrieval. The loss of the Challenger and the resulting hiatus in the Shuttle program caused considerable additional delay. The altitude of LDEF continued to decay, exacerbated by the near record solar activity of solar cycle 22 . When retrieved by the Orbiter Columbia on January 12 of this year, the altitude of LDEF was about 180 nautical miles. Although the batteries powering the onboard data system had long since run down and the resulting orbital time without performance data made it impossible to meet some of the original objectives, several important, unanticipated benefits have accrued. The atomic oxygen flux at the lower altitudes is much greater than that experienced during the majority of time on-orbit. The longer orbital time also increased the probability of micrometeoroid and debris impacts, a component of low earth orbit of particular interest to the performance of solar arrays.

During deintegration at the Kennedy Space Center photographic, radiation, and thermal surveys were conducted. Batteries were removed 
and their charge state measured. A detailed survey of micrometeoroid and debris impacts was also conducted. The experiment was returned to the Lewis Research Center via our Gulfstream aircraft on March 14. The Magnetic Tape Memory (MTM) recorder was removed and delivered to its manufacturer, Lockheed Electronics Company, for processing and data transcription. The flight data has since been loaded in to the Lewis Research Center's Scientific Vax Cluster for analysis.

\section{OBJECTIVES}

The experiment was designed to implement three specific objectives concerning the performance of space solar cells in the extraterrestrial solar environment. The first objective was to determine the performance and endurance of advanced solar cell designs under low earth orbit conditions. This was to be accomplished by the daily measurement and recording of the short-circuit current of 120 cells whenever the sun angle was optimum. The current-voltage characteristic of 16 cells was determined at the same time by measuring the open-circuit voltage and the cell current and voltage as defined by six different load resistors.

The second objective was to calibrate reference solar cells for use as intensity standards in laboratory solar simulators. The daily determination of short-circuit current and the concomitant solar intensity and sun angle data of the $120 \mathrm{I}_{\mathrm{Sc}}$ cells throughout the duration of the flight would satisfy the requirements of this objective.

The measurement of the energy distribution in the extraterrestrial solar spectrum was the final objective. Three instruments were included in APEX for this purpose. An absolute cavity radiometer measured the total solar irradiance when illuminated solar cell performance was being recorded. The measure of the broad band solar spectrum was obtained using a $45^{\circ}$ dichroic mirror to divide the spectrum into two roughly equal parts. Silicon cells were used as sensors. Sixteen narrow bandpass filters coupled with silicon solar cell detectors were used to measure the solar spectrum over a wavelength span of 0.3 to 1.1 micrometers. These filters could then be used for the calibration of a laboratory spectral response system.

\section{EXPERIMENTAL DESIGN}

The Advanced Photovoltaic Experiment was required to be completely self-contained in terms of control, data acquisition and storage and power. To attain maximum accuracy in cell calibration, it was desirable to minimize the amount of Earth reflected radiation reaching the cells. Since relative solar azimuth changes with time in orbit and the minimum relative solar elevation occurs at the terminator crossing, a slat-slot approach was used for the cell field-of-view (FOV) design. The cell's FOV is therefore small in the elevation axis and large in the cross-axis. The twelve inch deep, full size ( $50 \times 34$ inches) tray was divided into three bays. The smaller cells, typically two centimeters square or two by four centimeters and requiring less depth than larger cells to attain the proper FOV, are mounted in bays 1 and 3 . The larger area cells, requiring a greater depth, are mounted in the central bay 2 . 
The shallowness of bays 1 and 2 provides room for the electronic systems. The four batteries needed for power were mounted on the rear of the tray. Figure 2 shows APEX prior to integration with LDEF. Baffles located between the rows of cells further minimize reflection. The baffles and the underside and upper surfaces of the FOV plates were painted with Chemglaze Z-306 matte black paint. The lower half of the outside of the tray was similarly painted for thermal control purposes.

The Eppley cavity radiometer can be seen in Figure 2 as the round object in the upper part of the tray. Next to it is the Digital Solar Angle Sensor (built by Adcole Corporation) which measures sun angle on two orthogonal axes and enables optimal conditions to be selected for performance measurement. To the right of the DSAS is the dichroic mirror with its two silicon cell sensors. In the row below these instruments are the Barr Associates narrow bandpass filters which are mechanically clamped over the silicon cell sensors. Also included in the experiment are two ultraviolet exposure monitors. They are disks of fused silica which degrade in short wavelength transmittance as they are exposed to the ultra-violet rich AMO insolation.

The solar cells were mounted on removable aluminum plates, either singly or in pairs of smaller cells, using RTV 511 adhesive and primer. For the $120 \mathrm{I}_{\mathrm{SC}}$ samples, a precision $0.1 \mathrm{ohm}$ resistor was wired across the cell and mounted on the rear of the plate using insulated feedthroughs. Short-circuit current was easily determined by measuring the analog voltage across the resistor. The short-circuit current of the sensors cells in the dichroic mirror instrument and under the bandpass filters was determined in the same manner. The sixteen I-V cells had a six point current-voltage characteristic measured by the switching of a number of predetermined load resistors across the cell.

The temperature of many of the cells as well as several locations on the tray were measured and recorded by 128 sensors. Yellow Springs Instruments type 16429 thermistors (for space applications) were utilized. The thermistors were mounted in a slot machined in the aluminum cell mounting plate, directly beneath the cell. It was bonded into place with Eccobond 555 adhesive.

The experiment was designed to acquire performance data from the cell samples and associated instruments once per day while they are being illuminated by the sun, on those days when the orbital conditions allow such a measurement. Two distinct electronics systems provided this capability. One, the Langley provided Electronics Power and Data System (EPDS), provided timing signals, data storage, power to the experiment and an interface to LDEF for deployment initiation purposes. The other, the APEX Data Acquisition System performed the primary control and data acquisition functions. This system was designed and built by Gulton Industries under subcontract to Eppley Labs. The most optimum sun angle conditions for each data scan were insured by the DSAS.

After data acquisition was completed the data was transferred to the flight recorder, the MTM, through the EPDS. The data words were handled in a twelve bit format. Because the capacity of the EPDS was 4096 words per interrogation and that of the APEX electronics was 8000 words, the data was transferred in two scans, 12 hours apart. Upon receipt of the 
data, the EPDS wrote the data to the tape three times for redundancy. Every eight days a night scan was conducted, which enabled calibration of various instruments and a measure of the dark currents of the solar cells. This data was also recorded.

After fabrication and functional testing of APEX was completed at Eppley Labs, the experiment was shipped to Lewis for thermal-vacuum and vibration qualification testing. Final verification of system operation was performed at the Kennedy Space Center in November, 1983 prior to integration with LDEF. APEX, as was LDEF, was designed and constructed for multiple flights. This is no longer the case, as the entire experiment, not just the solar cells, is of considerable scientific and engineering interest.

\section{SOLAR CELL COMPLEMENT}

The solar cells on APEX were provided by a number of industrial and governmental institutions (Table 1) for calibration and return for use as reference standards. The cell complement represents the state-of-the-art in space photovoltaics as of mid-1982 as well as production cells and examples indicative of cells used on a number of satellites. Standards which had been previously calibrated using aircraft, rocket flights and high-altitude balloons were also included, as were radiation damaged cells. The majority of the cells are silicon, although gallium arsenide cells were included. Table 2 summarizes the cells types flown. Space limitations prevents listing all of the permutations of cells, coverglasses and adhesives.

\section{FLIGHT RESULTS}

The physical changes to APEX after experiencing the full effects of the ram for nearly six years are readily apparent. Figures $3-5$ are post-flight photos of the three bays of APEX. (Unfortunately many of these changes are not easily seen in black and white photos). A significant portion of the black paint has been removed from the upper surface of the field-of-view plates. The Chemglaze primer, reddish-brown in color, is visible. The differences from plate to plate in the amount of paint remaining is possibly a function of the initial thickness, as the plate covering bay 2 was painted at a different time than the other FOV plates. The top plate of the DSAS, originally bare aluminum, is now golden in color.

Contamination of a yet unknown composition and origin is found over much of APEX, as well as LDEF itself. A yellow-gold film is particularly evident on cells and mounting plates in the two rows nearest the space end of the tray. Discoloration is also seen on the baffle plates and the underside of the field-of-view plates.

The large number of white dots, most clearly visible on the black portions of the FOV plates, are impact craters from micrometeoroids and debris. A survey of APEX conducted by the LDEF Project Office at the time of deintegration yielded a count of about 600 impacts, the vast majority 0.5 millimeter in diameter or smaller. The largest crater has a 
diameter of about 2 millimeters. Among the impacted surfaces are the glass aperture of the DSAS, one of the bandpass filters and a number of solar cells. Damage to the cells includes cratered and cracked coverglasses, craters extending into the cell itself, and in one case, a small portion of a silicon cell and coverglass was removed as the particle continued into the aluminum substrate.

Preliminary analysis of the flight data indicates that the electronic systems functioned as designed. Photovoltaic data over the first 358 days of flight has been obtained. The Gulton system, providing this data, presumably ceased operation when its batteries discharged to below a threshold level, as the two 28 volt batteries powering the Gulton system were totally discharged when they were removed. The 358 day operational lifetime falls between the lifetime span of 233 to 467 days calculated prior to flight. The EPDS continued to function for 2017 days, nearly the entire orbital duration. It appears that the only data stored on the tape after day 358 was timing, synchronization and calibration words. Values of cell currents, voltage calibration data, the cavity radiometer heater current and thermopile signal are all within nominal, expected values. Detailed analysis of the data from the nearly 300 discrete signal channels has begun and is expected to continue into the foreseeable future.

\section{CONCLUSIONS AND PLANS}

Post-flight analysis of the Advanced Photovoltaic Experiment indicates that it successfully completed its mission and returned 358 days of solar cell and solar intensity and spectrum data. A number of physical changes are readily apparent, including micrometeoroid and debris impact craters, loss of black paint from the surface of the experiment and contamination.

The continued analysis of APEX will follow two parallel paths. The changes in coatings, the nature of the contamination and other material issues will be pursued. Investigations utilizing a number of available surface and chemical analysis techniques will begin once the experiment is dismantled. This dismantling will begin after the next stage of the second path is completed, functional testing of the entire electronics system. This test, scheduled for mid-June, when successfully completed, will be followed by removal of the individual cells for exhaustive electrical, optical and chemical testing. The cavity radiometer and digital solar angle sensor will be examined and their calibration checked by the manufacturers. The solar cells will be returned to the organizations holding title to them together with detailed flight and ground test data.

\section{ACKNOWLEDGEMENTS}

The authors would like to thank Donald Brasted of the Computer Services Division for his unflagging efforts in reduction and analysis of the APEX flight data; particularly difficult after a hiatus of nearly six years. We also wish to thank Richard Hoffman and David Scheiman of the Photovoltaic Branch for their invaluable assistance in post-flight processing. 


\begin{abstract}
ASEC
COMSAT

SOLAREX

SPECTROLAB

A. F. WRIGHT AERONAUTICAL LAB EUROPEAN SPACE AGENCY JET PROPULSION LABORATORY LEWIS RESEARCH CENTER MARSHALL SPACE FLIGHT CENTER
\end{abstract}

Table 1 - APEX solar cell investigators

Si: BSR/BSF

Violet

Vertical Junction

Textured

$5.9 \times 5.9 \mathrm{~cm}$ PEP

2 mil thick

GaAs: LPE
Standards: Balloon

Rocket

Airplane

Radiation Damaged

Covers: Fused Silica

Ceria Doped Microsheert

V- and U-Grooved

\footnotetext{
Table 2 - Summary of APEX cell types
} 


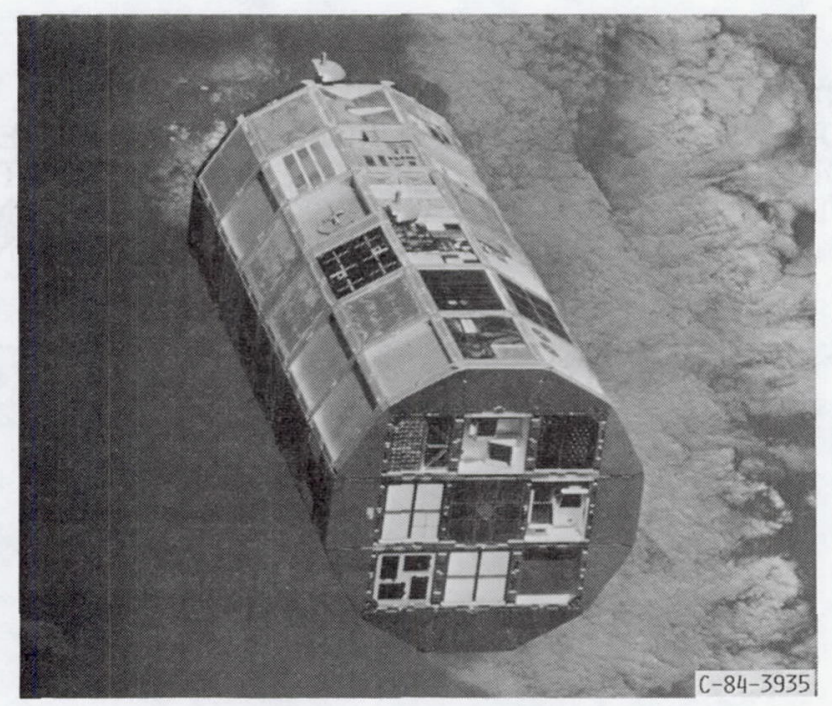

FIGURE 1. - LDEF AT THE MOMENT OF DEPLOYMENT.

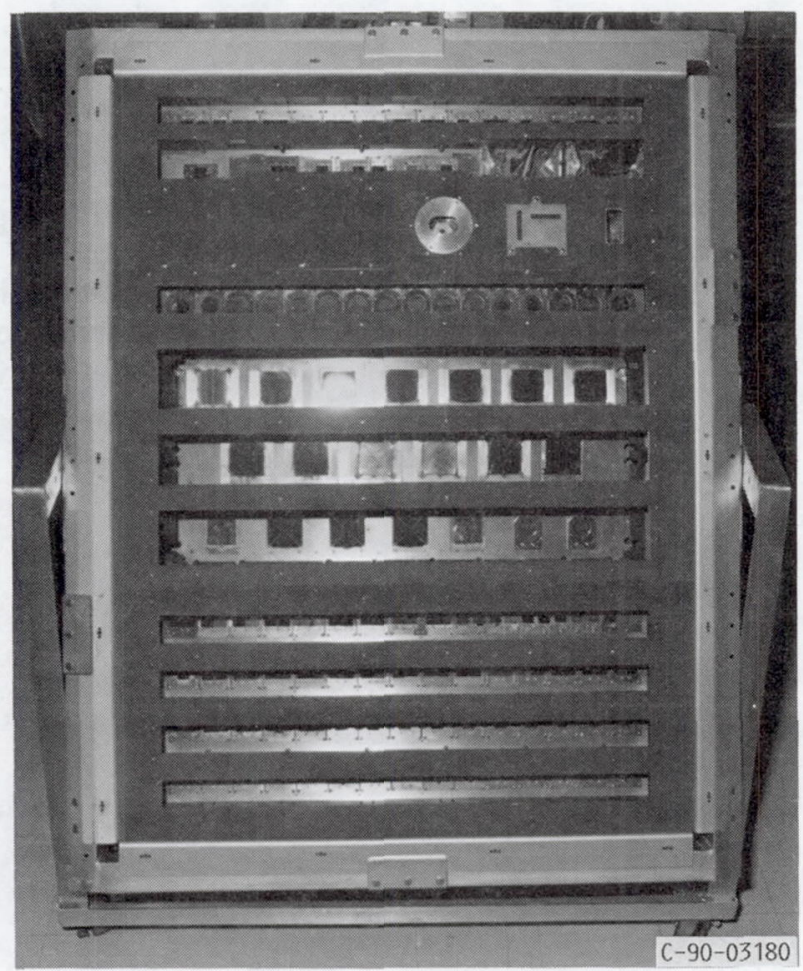

FIGURE 2. - APEX PRIOR TO INTEGRATION WITH LDEF. 


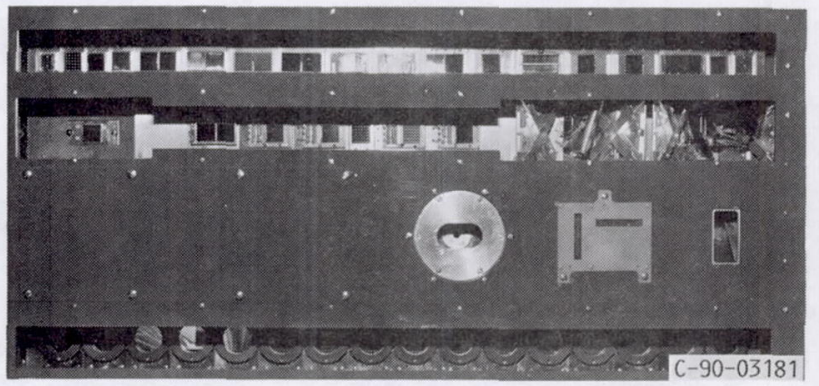

FIGURE 3. - POSTFLIGHT DETAIL, BAY 3.

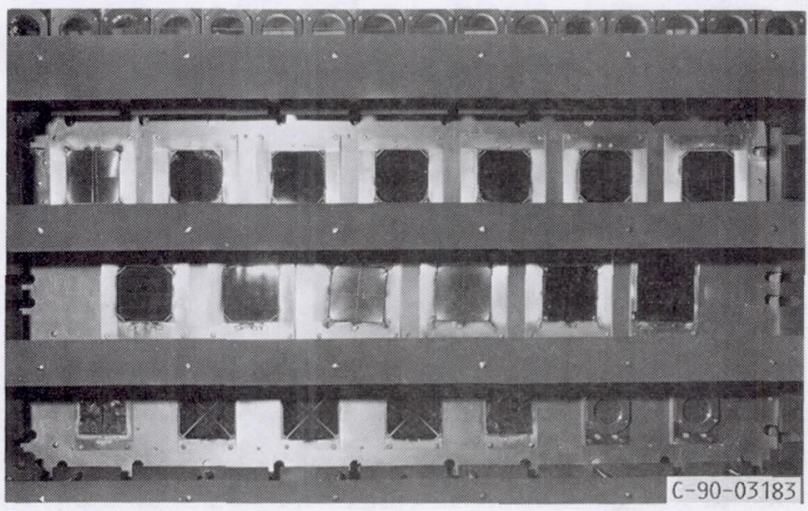

FIGURE 4. - POSTFLIGHT DETAIL, BAY 2.

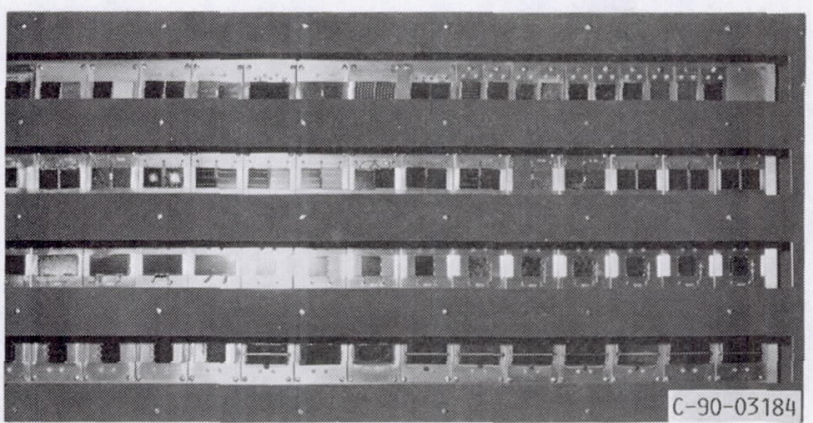

FIGURE 5. - POSTFLIGHT DETAIL, BAY 1. 


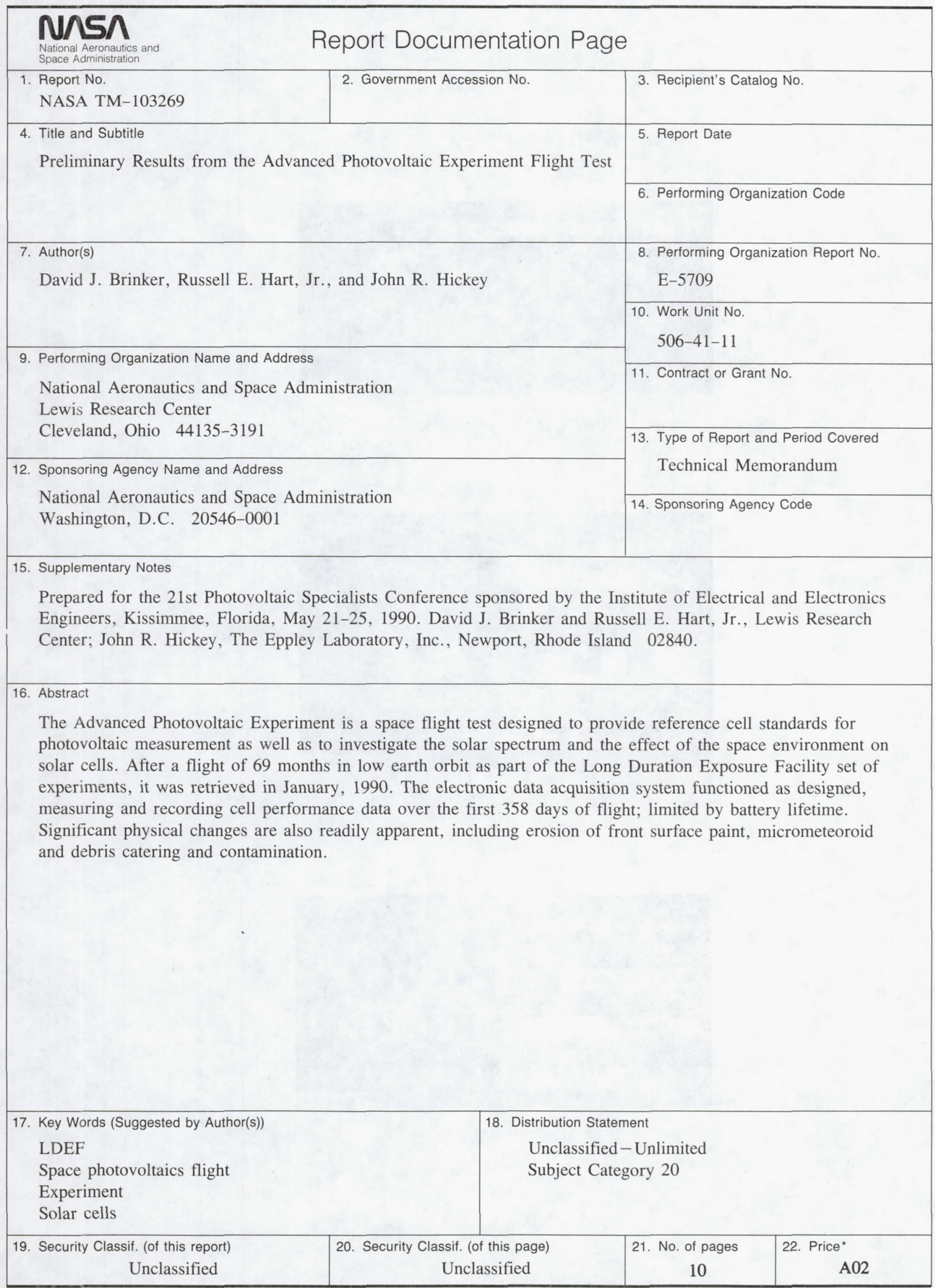

